\title{
Corrigendum
}

\section{Synthesis of the first mixed-donor spiro-linked macrocyclic tetralactams [Arkivoc 2008 (xvii) 205-211]}

\author{
Ahmed H. M. Elwahy, ${ }^{\text {a,b }}$ Hussni A. Muathen, ${ }^{a}$ and Nour A. M. Aloweiny ${ }^{\mathrm{a}}$ \\ ${ }^{a}$ Makkah Almukkarramah, P. O. Box 6503 unit 113, Saudi Arabia \\ ${ }^{b}$ Chemistry Department, Faculty of Science, Cairo University, Giza, Egypt \\ E-mail: aelwahy@hotmail.com
}

The authors apologize for the following omission from the above paper.

\section{Acknowledgments}

The authors would like to thank King Abdul-Aziz City for Science and Technology in Saudi Arabia for generous support of this work. 